\title{
Exploring impact investing's emergence in the philanthropic sector
}

\section{Jessica Jones and Elizabeth Embry}

Impact investing has received widespread attention in recent years, reaching $\$ 502$ billion in assets under management in 2019 alone (Mudaliar et al., 2019). Though practiced informally for decades, impact investing did not become formally classified until 2007 (Bugg-Levine and Emerson, 2011). Defined as investments made with the intention of generating positive, measurable social and environmental impact alongside a financial return' (Global Impact Investing Network [GIIN], 2019, p. ii), impact investing has gained recognition and adoption across finance, government and philanthropic sectors (Agrawal and Hockerts, 2019). Some describe impact investing as the practice of 'philanthropic objectives with mainstream financial decision making' (Höchstädter and Scheck, 2015, p. 449). Growing global adoption across private and public organizations points to the importance of the phenomenon and the need to understand it, especially as it is utilized alongside other funding strategies (Mudaliar and Dithrich, 2019).

Although it is a multi-sector practice, definitions of impact investing have provided little distinction between how different funders from different sectors uniquely incorporate impact investing within their current practices to achieve their organization's mission. Many funding organizations in the finance sector have adopted the practice due to the purported opportunity for investors to achieve social returns without compromising the benefits of financial returns (Gregory, 2016; Mudaliar and Dithrich, 2019). However, for organizations in the philanthropic sector, the notion of creating funding mechanisms to generate financial return alongside their charitable purpose presents a paradigm shift (Bell, 2013). Thus, it is not surprising that while the pool of capital devoted to impacting investing has rapidly increased, the philanthropic sector has been slower to adopt this funding practice (Emerson, 2018). Of the $\$ 502$ billion in assets allocated towards impact investments, less than 3 percent of 
those dollars come from organizations in the philanthropic sector (Mudaliar and Dithrich, 2019).

Defined as individuals, organizations and branches of corporations dedicated to engaging in charitable or philanthropic activities for humanitarian and environmental purposes (Payton and Moody, 2008), the philanthropic sector has historically been resistant to the notion of generating a financial return on their activities (Balboni and Berenbach, 2014; Moody, 2008). However, the rise of impact investing practices is timely for the philanthropic sector, as it has evolved in recent years in response to critiques purporting charitable giving as unsustainable and ineffective at addressing long-term, systemic social issues (Rath and Schuyt, 2014; Roundy, Holzhauer and Dai, 2017). Despite the low dollar amount allocated towards impact investment in the philanthropic sector thus far, philanthropic organizations are uniquely positioned to influence the growing phenomenon (Porter and Kramer, 1999; Tekula and Shah, 2016).

This chapter aims to shed light on emerging questions that rest at the intersection of philanthropy and impact investing. To help advance this necessary conversation, this chapter is organized as follows. First, we describe the evolution of impact investing, its purported appeal to and involvement of the philanthropic sector. We then unpack characteristics of the philanthropic sector, specifically focused on philanthropic organizations and the unique features that distinguish them from other types of funders who have adopted impact investing practices. In this discussion, we shed light on the shift in the philanthropic sector from being described and treated as simply charity, to the evolving ways its social mission and funding strategies can be utilized to address systemic societal issues.

By unpacking the complexity of the philanthropic sector, scholars and practitioners can more fully capture how the practice of impact investing can be adopted by philanthropic organizations, and with what challenges. As impact investing is an emerging phenomenon, especially within the philanthropic sector, it is important to engage scholars at the micro and macro levels across diverse fields, such as management, organizational behavior, strategy, entrepreneurship, economics and finance, to gain a more comprehensive perspective. To aid this exploration, we present future research questions at the individual, organizational and institutional levels of analysis. Ultimately, this chapter facilitates more exploration around the intersection of philanthropy and impact investing, pointing to questions that may explain impact investing's purported appeal yet slow adoption by the philanthropic sector and existing future opportunities for growth and impact on the pressing social and environmental issues. 


\section{Aligned opportunities: impact investing and the philanthropic sector}

Impact investing, the practice of directly creating positive, measurable social and environmental impact alongside a financial return, stemmed from a series of events that called society to rethink long-term outcomes of financial markets. Socially responsible investing and corporate social responsibility (Battilana and Dorado, 2010; Santos, Pache and Birkholz, 2015) were becoming well-accepted practices when the United States' financial crisis took place in 2008. The concept of impact investing formally emerged a year earlier from a group of institutional investors and philanthropists, including The Rockefeller Foundation, Acumen Fund, and B Lab (Bugg-Levine and Emerson, 2011). This group then formed the GIIN as a non-profit convening body to facilitate knowledge exchange, build infrastructure and develop research to accelerate the development of a coherent impact investing movement that was cross-disciplinary and amenable across multiple sectors (Höchstädter and Scheck, 2015).

Built from the assumption that there is not enough charitable and governmental capital to meet increasingly pervasive social and environmental challenges, impact investing aims to fill this gap by engaging multiple sectors to focus on the purpose of generating positive impact and change. What makes impact investing unique is the claimed paradigm shift away from the belief that financial and social returns should be mutually exclusive (Emerson, 2003). Impact investing certainly purports many benefits and has generated optimism for the philanthropic sector's ability to meet both social and financial demands (Bolis and West, 2017). However, it is important to fully understand the characteristics and norms of the philanthropic sector in order to understand its relatively low adoption rate of impact investing in comparison to the finance and government sectors (Koh, Karamchandani and Katz, 2012).

The philanthropic sector has been and continues to be well positioned to incorporate a practice like impact investing, given its own evolution. For decades, the philanthropic sector demonstrated the incorporation of impact investing characteristics, such as monitoring and searching for long-term funding recipients (Agrawal and Hockerts, 2019; Brest and Born, 2013). As early as the 1960s, private foundation leaders such as John D. Rockefeller began incorporating accountability and investment approaches in how they engaged with their funding recipients (Arrillaga-Andreessen and Hoyt, 2004; Cobb, 2002). Subsequently, other philanthropic organizations began adopting financing approaches used in the private market. For example, the Center for 
Venture Philanthropy in Silicon Valley spearheaded the use of venture philanthropy, a practice by funders that encourages high engagement, accountability and exit strategies for their non-profit funding recipients (Moody, 2008).

Because of limited financial resources for grant making, the philanthropic sector has a 'tremendous appetite for innovations to improve effectiveness and sustainability, including those [innovations] that seek to direct the power of private markets' (Koh et al., 2012, p. 7). Practices such as responsible investing and mission-related investing allow philanthropic organizations to align their donor dollars with investments that affect their social mission (Hebb, 2013; Roundy et al., 2017). In addition, program-related investing allows philanthropic organizations to improve upon traditional grant making by adopting techniques used by venture capital firms that advanced the accountability and move towards financial sustainability for their recipients (Letts, Ryan and Grossman, 1997). Each of these practices can be considered a form of impact investing as the term integrates a spectrum of financial strategies used to achieve their philanthropic goals. Specific strategies range from the engagement of more traditional grants to include financial considerations, to the inclusion of social reporting in traditional investments, with more balanced approaches in between (Hebb, 2013; Höchstädter and Scheck, 2015).

Under the umbrella of impact investing, each of these financial strategies has been designed in a way that improves the effectiveness of philanthropic dollars. It is quite surprising then, that relatively few philanthropic organizations are adopting impact investing practices. This chapter lays the groundwork for exploring this puzzle: if impact investing is meant to be adopted across multiple sectors, why are so few from the philanthropic sector engaging in the practice?

In order to answer this question, a deep dive into the philanthropic sector is essential. Current literature in management, strategy, economics and finance oversimplifies the philanthropic sector by mostly discussing philanthropy as an arm of corporate giving (e.g., Brown, Helland and Smith, 2006; Saiia, Carroll and Buchholtz, 2003), or labeling it as only direct, charitable activity (e.g., Cain, Dana and Newman, 2014; Jeong and Kim, 2019). A more in-depth overview that describes how philanthropic organizations within the sector are structured, receive funding and allocate their dollars is necessary to then address the intersection of the sector and impact investing. 


\section{The philanthropic sector: uncomplicating organizational structures and strategies}

The origins of philanthropy come from the root word 'phil', meaning 'love of mankind' (Merriam-Webster, n.d.). Philanthropic activity aims to serve a public good, usually through private means (Wood and Hagerman, 2010). For the purposes of clarity in this chapter, we will separate direct charitable giving from philanthropic practices, which is the focus. Direct charitable giving occurs when an individual provides money or in-kind gifts to independent causes or solicitations without a formalized agenda or plan for their giving (Wright, 2001). In contrast, philanthropic practices are the intentional giving of funds to identified individuals and organizations to fulfill a specific mission and designated strategy (Wright, 2001). Philanthropic giving, from here on referred to as philanthropy, often comes from individual or corporate wealth. Philanthropic organizations are established to facilitate the giving of those funds to individuals and organizations, typically non-profits, working to make a positive impact on a social or environmental cause. Further, the practice of establishing philanthropic organizations enables the separation of an individual or organization's philanthropic work from their primary business in both activity and legal manners.

While grouped into the same sector, there are many different types of organizations that comprise the philanthropic sector. We briefly describe the most common types of philanthropic organizations and explain the differences in organizational form, how they engage in philanthropic activity, and how they fund those activities. This list is not meant to be exhaustive as there are many variations within the descriptions that follow. Rather, we describe the diversity of organizational forms and funding mechanisms in the philanthropic sector. In doing so, we demonstrate the importance of these nuances in exploring the emergence of impact investing within the philanthropic sector.

\section{Philanthropic organizational forms}

\section{Public charities}

Public charities are organizations that raise money from the public to support organizations and individuals working to achieve the charity's goals. Public charities are funded by individuals, corporations and some foundations, and their primary method of giving is through traditional grants (Brown and Metter, 2019). Given that their funds are established through a diverse set of donors, these organizations are not classified as a foundation (Sansing, 2010). Public charities are established as non-profits and typically have an operating 
endowment; however, unlike foundations, they are required to have leaders and board members that represent the public that is being served (Calabrese and Ely, 2017). One of the most well-known public charities is United Way. ${ }^{1}$

\section{Private foundations}

Private foundations are non-profit, non-governmental organizations that are typically funded from a single source: individual, family or corporation. These foundations are established as either charitable trusts or non-profit Internal Revenue Service (IRS) section 501(c)(3) corporations, and thus tax-exempt in the United States. To maintain their status, private foundations are legally required to disperse at least 5 percent of their endowment's income each year (Wexler and Fei, 2019). Private foundations are classified as either operating or non-operating. An operating private foundation utilizes their funding themselves to reach their charitable goals, and may offer a few grants to related organizations. Primary examples of operating private foundations are museums, research groups and think tanks (Sansing, 2010). A non-operating private foundation disperses their funds to other organizations who are working in the areas of the foundation's missions and goals (Sansing and Yetman, 2006). Non-operating private foundations are the most common type of private foundation, and can be further classified by their funding source.

\section{Corporate foundations}

Corporate foundations are established primarily through the funds of a for-profit business. These company-sponsored foundations are independent organizations but retain close ties to their donor corporation. Many corporate foundations have a mission to give back to the communities where their employees are located, support philanthropic concerns of their customers or to strengthen their brand. Additionally, corporate foundations can be used to provide employee matching grants or administer scholarship programs for employees' families or customers. According to the Giving USA Foundation, there are more than 2600 corporate foundations in the United States whose grant making in 2018 totaled $\$ 6.88$ billion, up 6.5 percent from the previous year (Brown and Metter, 2019). Well-known examples of corporate foundations include the Ford Motor Company Fund ${ }^{2}$ and the Coca-Cola Foundation. ${ }^{3}$

\section{Family foundations}

Family foundations are created through funds given by at least one member or a group of members of a single family, and require that at least one member 
of that family must continually serve as a leader or board member of the foundation, at all times (Gersick et al., 2004). Typically, family foundations are established to support organizations with missions that align with the family's interests and values. These foundations vary substantially in organizational size, structure and scope of giving, ranging from large international reaches, such as the Bill \& Melinda Gates Foundation, ${ }^{4}$ to small foundations focused on a single issue or geographic location.

\section{Community foundations}

Community foundations are foundations established through a permanent fund created by a group of donors. Typically, a community foundation serves the needs of a specific geographic region (Graddy and Wang, 2009). In addition to giving funds, community foundations also support donors who want to create endowed funds but do not have the means of starting their own independent foundation. There are currently more than 750 community foundations in the United States (Council on Foundations, 2021).

\section{How philanthropic organizations engage in charitable activity}

Guided by their mission and goals, there are many different funding mechanisms that philanthropic organizations use to disperse funds to individuals and organizations working to advance their social or environmental mission. This overview is intended to introduce basic existing practices of philanthropic organizations to illustrate some of the contextual uniqueness prior to discussing their involvement with impact investing practices.

While some philanthropic organizations accept direct solicitations for funding consideration, most have a formal process to receive grant applications. The most common is a request for proposal (RFP) which outlines specifics about the type of funds being offered, eligibility of applicants, required application materials, and timeline for funding and reporting. The following are the most common types of RFPs, typically allocated as a grant (Brown and Metter, 2019):

- Project grants are the most traditional form of grants as funding is given to support a specific program or project for a designated period of time.

- Capacity-building grants allow the recipient organization to increase their abilities or expand their services. These grants are for a process rather than a project.

- Operating fund grants are designated to support overhead costs like staffing and physical infrastructure needs. 
- Sponsored research grants provide financial support for scientists and laboratories at universities or research-oriented non-profit organizations. These grants are typically focused around a specific disease, animal species, or novel phenomenon.

- In-kind grants provide non-monetary assistance such as equipment, office space, meeting space, and pro bono personnel. These grants are most often given by corporate foundations.

In addition to these types of grants, some foundations provide their board members and staff members with specific amounts of funds to use at their own discretion to support special causes or ideas they are personally connected with. This type of discretionary grant making can foster new enthusiasm and partnerships, but also run the risk of diverting the focus of the foundation's mission. Similarly, many of the larger foundations offer special cause or emergency funding to offer assistance when there is a critical, short-term need including natural disasters, equipment failure, or civil disturbance.

\section{How philanthropic organizations finance charitable activity}

Up to this point we have discussed how philanthropic organizations are established and disperse money to achieve their social mission. In order to disperse this money, philanthropic organizations rely on funders themselves to fund their activities. Public charities rely on the public, often from smaller donors, whereas foundations rely on an individual, community, family, or corporations to provide the funds to establish an endowment (Fidelity Charitable, 2019). An individual or team is then charged with the goal for the endowment to exist in perpetuity in order to annually allocate money in the form of charitable activity.

Structurally then, the majority of philanthropic organizations' assets exist in investments expected to grow at a rate at which they can then distribute a portion annually to individuals and non-profit organizations (Sansing and Yetman, 2006). Private foundations are required to allocate at least 5 percent of their net assets toward charitable purposes annually (Wexler and Fei, 2019). Traditionally, then, philanthropic organizations segregate their investment and philanthropic activities structurally by having some staff manage the investment portfolio to maintain the growth of the foundations' assets and other staff focus on programs related to philanthropic giving, typically in the form of grants (Mintz and Ziegler, 2013). Impact investing is a unique opportunity for both investment and program areas to adopt new practices; we next turn to the ways in which both grant-making and investment strategies have shifted to include impact investing. 


\section{Adoption of impact investing by philanthropic organizations}

\section{Shifts in traditional grant-making strategies}

While there will always be a need for strictly charitable grants that enable organizations to start new initiatives and pilot new solutions, this generates no financial return and requires non-profits and recipients of philanthropic dollars to continue to source funds from their donors. Recently, many non-profit executives discussed how they entered into their work because they were deeply passionate about the cause, but now find themselves constantly chasing funding, piecing together numerous grants to support their staff teams, and trying to keep up with the reporting requirements for each grant received, rather than working to directly implement their solutions (Kanter and Sherman, 2016). Ultimately, achieving a social mission by solely engaging in traditional grant making does not address systemic solutions to deep social concerns. This has led philanthropic organizations to rethink their funding strategies. Questions remain as to how the philanthropic sector can unlock capital that is traditionally given away to be used as recyclable capital. How can philanthropic organizations move to integrate investment behavior with philanthropic behavior to promote more sustainable financing and opportunities to address more systemic solutions to social issues?

Impact investing has created a way to provide continued investments over a longer time horizon to support an initiative, and simultaneously also provide some financial return to the philanthropic organization that can be further used to support the mission. Advocates of impact investing have argued that philanthropic organizations can adopt low-risk financial instruments - for example, in the form of a loan rather than a traditional grant - that recycle some capital. This transition towards investment practices is not meant to substitute for all grants, but is an additional step for a recipient to move towards financial sustainability. As discussed, the philanthropic sector is ripe for innovation and has been called to 'leverage every single tool and asset and resource at your [philanthropic organization's] disposal to ensure that you have the maximum impact on society that you can possibly have'. ${ }^{5}$

Some philanthropic organizations that have adopted impact investing proceeded with a tiered approach. For example, Blue Meridian Partners, ${ }^{6}$ focused on transforming the lives of families and youth, offers initial grants and then has a scaled approach to investing in organizations to ensure their recipients' success with successively larger investments over time. This movement into impact investing ensures that the recipient is positioned to be able to utilize the 
funding without it overwhelming their programmatic capacity, and also maximizes Blue Meridian's financial return on investment. Similarly, ZOMALAB, ${ }^{7}$ which has a specific geographic focus in their funding priorities, has established traditional grants for immediate needs for education and health care, and impact investing for longer-term strategies like energy and water.

Opportunities and challenges of integrating impact investing into philanthropic organizations

Impact investing is appealing to philanthropic organizations for several reasons. First, philanthropic organizations have the capacity to be innovative and influential in a variety of ways. Philanthropic organizations can use impact investing directly as a way to improve accountability and social performance of their recipients, educate and attract other funders to support similar social issues, and advance the state of knowledge through funded research (Jaskyte et al., 2018; Porter and Kramer, 1999). Second, philanthropic organizations typically operate on a longer time horizon than mainstream finance investors, as they are founded with the purpose to exist in perpetuity (Reich, 2019). Third, since the formalization of impact investing, younger leaders, who are more likely to be open to innovation and new practices, have transitioned into executive positions at philanthropic organizations (Van Slyke and Newman, 2006; Wood and Hagerman, 2010).

Despite impact investing's purported appeal, evidence points to a relatively slow adoption rate by philanthropic organizations in comparison to mainstream finance investors. This may be due to the following challenges that philanthropic organizations face in incorporating impact investing practices.

First, as previously discussed, impact investing practices are relatively broad. The challenge for philanthropic organizations may not necessarily be in understanding why impact investing can be incorporated, but how and to whom. It may also be unclear to a philanthropic organization exactly what financial instruments should be adopted to begin impact investing, and how to effectively do so (Koh et al., 2012). Incorporating new funding mechanisms also require different forms of analysis to measure return on investment of funds given. Thus, organizations must have the internal capacity to adopt the new practice, as well as educate their funding recipients and key stakeholders on the differences in practice, expectations and measurement.

Another challenge is that the use of private capital financing instruments clashes with the existing institutional norm of philanthropic giving (Reddy, 2015; Roth, 2020; Roundy et al., 2017). While impact investing purports 
that generating positive social and environmental impact can be integrated into the mission of philanthropic organizations, philanthropy originated by distinguishing itself from the private market (Gripne, Kelley and Merchant, 2016; Onek, 2017). The philanthropic sector has typically separated philanthropic and investment activities, both structurally and cognitively (Gregory, 2016; Hehenberger, Mair and Metz, 2019). Thus, philanthropic organizations may feel that giving and investing are substitutes, rather than complements (Glänzel and Scheuerle, 2016). Additionally, adopting impact investing may be perceived as a shift away from supporting the public good and social needs. This perception comes with the risk of losing legitimacy and support from the philanthropic sector at large if they adopt impact investing practices because, apart from some strong pioneers, it differs from current institutionally accepted norms (e.g., Phillips, Lawrence and Hardy, 2000). Overcoming these challenges requires additional research and education for stakeholders involved at the intersection of impact investing and the philanthropic sector.

\section{Future research}

The distinctive features of philanthropic organizations both challenge existing paradigms and creates new research opportunities for understanding its intersection with impact investing. We have noted that philanthropic organizations are comprised of dynamic individuals, are complex regarding their design and structures, and balance multiple institutional norms that often differ. Therefore, we propose research opportunities at the nexus of philanthropic organizations and impact investing at multiple levels of analysis: individual, organizational and institutional. Table 1.1. outlines how each level of analysis is defined, examples of actors and entities that can be studied at that level of analysis, exemplar research questions and corresponding theories. We next elaborate on this table to generate research ideas that may challenge, elaborate and refine theory pertaining to the overlap of philanthropy and impact investing. 


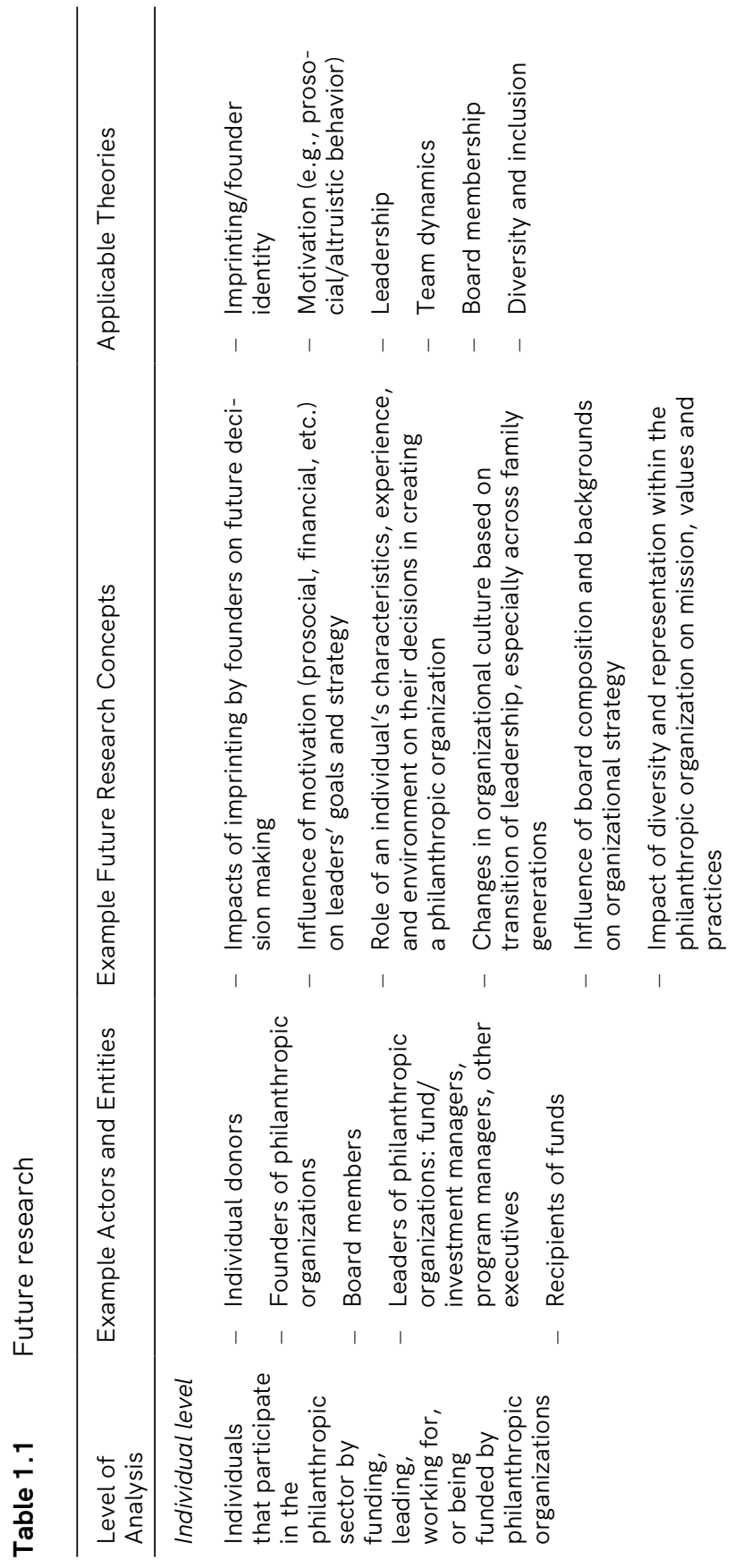




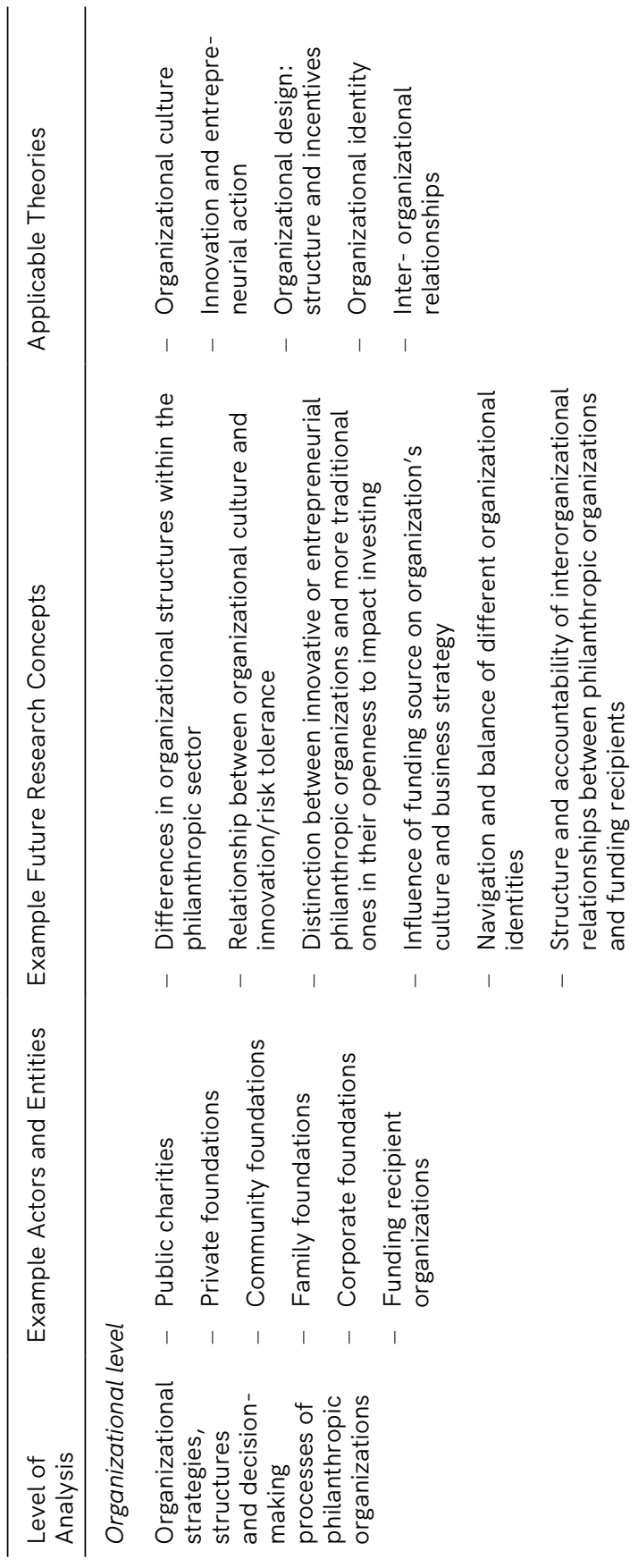




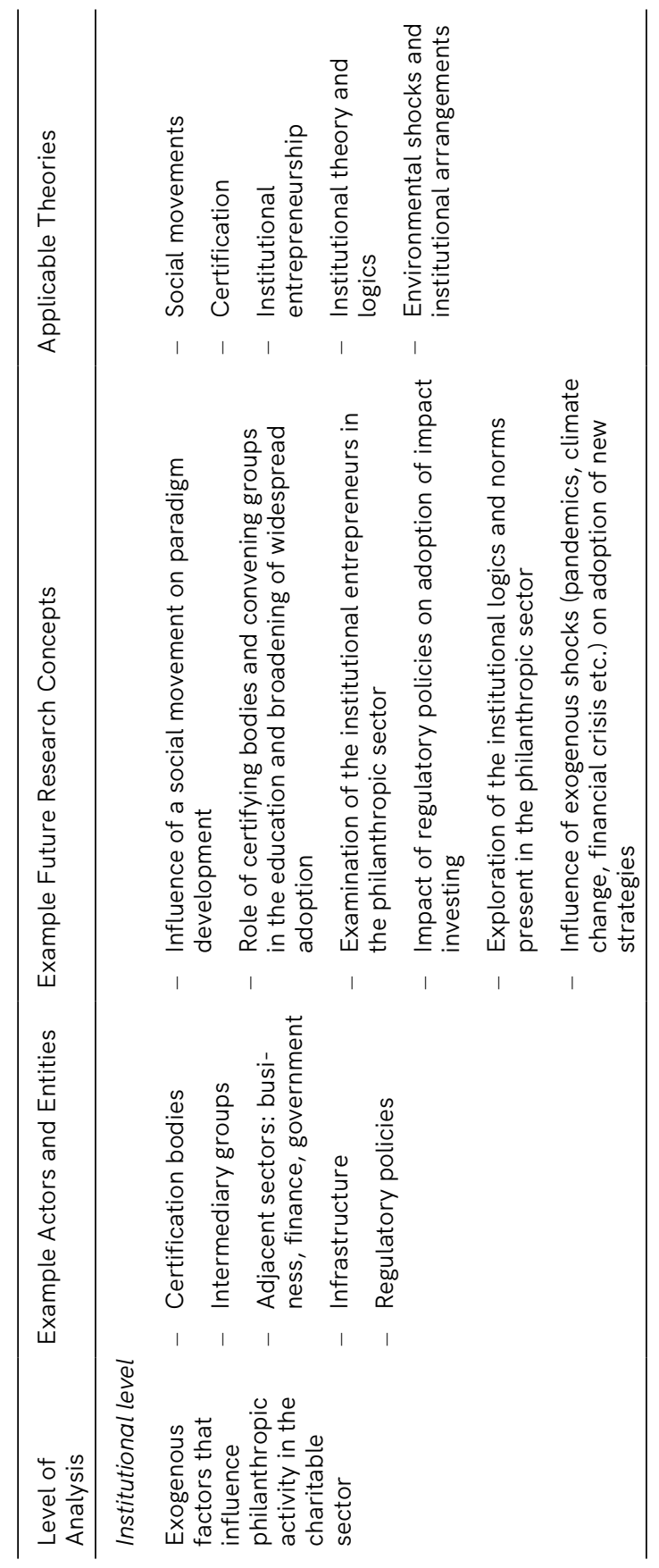




\section{Individual level}

Individuals who establish, lead, are employed by, and are funded by philanthropic organizations vary in their motivations, values and identities. Thus, there is a need for scholars to examine the adoption of impact investing by philanthropic organizations at the individual level. While our focus in presenting a possible research agenda is largely focused on founders and leaders of philanthropic organizations, it is important to note that recipients of funding are also impacted by the adoption of impact investing and should be considered in future research endeavors.

It is well established that founders' characteristics shape initial firm characteristics, policies and practices (Boeker, 1989). This imprinting effect, the characteristics that reflect prominent organizational features that persist over time (Marquis and Tilcsik, 2013), will differ depending on the unique individuals and their environments. For example, wealthy individuals who create private foundations in later stages of their lives may approach their organizations differently from individuals forming community foundations, based on the influence of their different situations and contexts. Further, future research examining organizational behaviors may also explore how organizational characteristics are imprinted by the founders and their behaviors at the time of formation.

Research on imprinting has also explored how early-career experiences impact the trajectory of one's career (Azoulay, Fons-Rosen and Graff Zivin, 2019; Tilcsik, 2013). How might early-career experiences influence individuals who form philanthropic organizations? Perhaps some individuals may be more prosocially motivated, whereas others may be more financially motivated (Batson and Powell, 2003; Grant and Berry, 2011; Shepherd, 2015). Exploration of such differences may explain the openness to practices like impact investing. This brings to light questions about how prior individual experiences influence organizational decision making.

While the link between founders' leadership styles and characteristics embodied in the organizational culture is well established (Bird, 1988; Schein, 1983), research suggests that leadership linked to innovation deserves much greater attention (Borins, 2002). This context may be useful to explore how founders' leadership characteristics influence the willingness for philanthropic organizations to explore new practices and take risks, including the adoption of impact investing practices. Then to take this research one step further, philanthropic organizations typically last across generations, which opens up questions of leadership transition to a new generation of family members or 
hired executives. Therefore, attention and comparison of original founders and current leadership of philanthropic organizations may also generate interesting insights related to leadership and motivation. Questions can also explore whether differences in leadership characteristics lead to openness for new strategies, such as integrating impact investing.

Other individuals within the organization are also likely to influence whether and how impact investing is integrated. In addition to members of the management team, board members of philanthropic organizations play a significant role in organizational decision making and support (e.g., Cha and Abebe, 2016; Lungeanu and Ward, 2012). In this context, board members from business backgrounds may exude the expertise and knowledge necessary to incorporate the requisite financial mechanisms for impact investing. At the same time, board members from public sector backgrounds may influence the resistance or hesitancy of adopting impact investing. Exploring board members' backgrounds and their interactions may generate important nuances to how new practices are negotiated and instantiated.

Finally, research is needed to explore the role and impact of diversity, equity and inclusion across the leadership, employees, board and funding recipients (Coffey and Wang, 1998; Wagner, 2016). Whether the founder and leadership of the philanthropic organization represent or belong to the population that is directly experiencing the social issue of the organization likely impacts how funding is allocated. Does the board have personal experiences that give voice to the needs of the community being served (Serafeim, 2018; Wry and Haugh, 2018)? These questions influence decisions being made by the philanthropic organization, and the knowledge of what funding strategies best serve their funding recipients. Research is needed to understand how the composition and intention of diversity across the leadership influence the mission, issues and practices of the foundation.

\section{Organizational level}

An additional contribution of this chapter is that it highlights intricacies among and within philanthropic organizations. While all philanthropic organizations share the common goal of creating positive social and environmental impact, more research is needed to disentangle the influences of organizational design and structure on the involvement of impact investing activities. This research requires scholars at the organizational level to explore the organizational strategies, structures, and decision-making processes of philanthropic organizations. 
Existing research largely assumes that organizations within the same sector (e.g., philanthropy) share common characteristics (e.g., Aldrich and Fiol, 1994; Carroll and Hannan, 2004; DiMaggio and Powell, 1983); however, our work here demonstrates that is not the case. Different philanthropic organizations have different funding structures and requirements, which is linked to other characteristics such as motivation and risk tolerance. Instead of grouping all philanthropic organizations together, there are opportunities to identify nuances across organizations and thus explore the role of these differences in adopting and implementing impact investment practices (Sanders and Tuschke, 2007; Waldron, Fisher and Pfarrer, 2016). Future work should shed light on both the rationale behind and the consequences of these nuanced structures across philanthropic organizations. For example, does organizational structure create or hinder opportunities for innovation? Further, what structural conditions influence the level of motivation and risk tolerance needed for adopting new financing strategies?

Organizational culture is another important consideration as it impacts internal strategy and operations, and helps define the organization to its stakeholders (Hatch and Schultz, 1997; Markus and Kitayama, 1991). In philanthropic organizations, the mission, the scope of social issues supported and the internal operations influence organizational culture (Payton and Moody, 2008; Schein, 1983). Questions about culture are pertinent in this context because certain cultures not only help audiences to make sense of what an organization is, but also how organizations may engage in the integration of impact investing. For example, entrepreneurial organizations may demonstrate more interest in adopting impact investing than legacy-focused organizational cultures because of their innovative culture (Cortimiglia, Ghezzi and Frank, 2016; Guth and Ginsberg, 1990). Corporate business cultures that influence corporate foundations may align more closely with the principles of impact investing, leading to a higher likelihood of designing riskier impact-investing funds. Research can be used to create a deeper understanding of how different organizational cultures influence or are in turn influenced by the funding strategies adopted.

Additionally, organizational identity, those organizational characteristics that are central, enduring and distinctive (Albert and Whetten, 1985; Pratt et al., 2016), create an interesting set of unexplored opportunities and challenges for philanthropic organizations. While it is well known that organizations have multiple identities (Foreman and Whetten, 2002; Pratt, 2016), it is unclear how multiple identities that a philanthropic organization holds will interact with the opportunity to integrate impact investing practices. For example, philanthropic and financial identities exist within every philanthropic organization, but their relative strength may influence the likelihood to adopt impact invest- 
ing practices. How foundations navigate, balance and make decisions based on their complementing or competing identities is worthy of future attention.

In addition, the interorganizational relationships that philanthropic organizations share with their funding recipients are unique in comparison with other funders who use impact investing strategies. The adoption of impact investing by philanthropic organizations shifts the relationship with their recipients from being solely a beneficiary to becoming both a beneficiary and an investee. While the principal-agent framework is a common characterization of funding relationships between investors and entrepreneurs (De Clercq et al., 2006; Sapienza and Gupta, 1994), whether and how the dyadic relationship between philanthropic organizations and their recipients adopts the tenants of principal-agent roles is less understood. Future research asks whether more accountability to recipients via principal-agent relationships leads to highly generative financial and social value. When a philanthropic organization adds additional financial instruments in order to achieve its mission, a higher sense of accountability is required to either repay or grow the capital provided to the recipient. Further understanding is needed about how the relationship between philanthropic organizations and recipients shifts when the financial instrument is a grant, loan or other form of impact investment (Glänzel and Scheuerle, 2016; Tekula and Shah, 2016).

At a relational level, scholars studying identity and work relationships can also extend knowledge about the mechanisms driving charitable, financial and hybrid relationships between philanthropic organizations and their recipients (e.g., Heaphy et al., 2018; Sluss and Ashforth, 2007). Examining this relationship leads to several interesting questions. What combinations of relationships between philanthropic organizations and funding recipients are possible, and how do these relationships evolve over time? Scholars studying identity (Ashforth, Rogers and Corley, 2011; Ashforth, Schinoff and Brickson, 2020; Barney et al., 1998) and power dynamics (Hehenberger et al., 2019) can further expand on the funder-recipient relationship across philanthropic organizations, or compare philanthropic organizations to other impact investing funders.

\section{Institutional level}

The previous sections presented opportunities for exploring the intersection of philanthropic organizations and impact investing at individual and organizational levels. It is also important to examine how philanthropic organizations are embedded in particular contexts that carry different institutional norms and expectations. Institutional-level analysis should explore different forces that 
influence the philanthropic sectors' integration of impact investing, such as the targeted social issue (e.g., health or housing), larger membership organization (e.g., Foundations and Donors Interested in Catholic Activities - FADICA), or geographic location (e.g., North America or Africa). Philanthropy is often positioned within the culture and/or region where their funding recipients are located. While this chapter takes the perspective of philanthropic organizations based in the United States, it is important to consider the cultural, political and regulatory influences in different environments. Theorizing the intersection of philanthropic organizations and impact investing is incomplete without an examination of how complex institutional environments impact organizational decisions.

One major trend within the impact investing movement is the focus on paradigm consensus, both in what impact investing is and how it should be measured (Costa and Pesci, 2016; Rawhouser, Cummings and Newbert, 2019). Although discussions about the specific definitions of impact investing, socially responsible investing and venture philanthropy are stimulating (see Agrawal and Hockerts, 2019; Trelstad, 2016 for reviews), it is also important to further refine our understanding of how the overall movement of impact investing is emerging in diverse sectors. For example, how does non-market strategy play a role in the integration of impact investing? What role do powerful actors have in influencing the paradigm development, and with what consequences? The GIIN emerged and formally coined the term impact investing in 2007 (Emerson, 2018). Fruitful research could direct scholars to understand potential pitfalls and opportunities that can be learned by the creation of a convening group that is relevant to organizations in multiple sectors, such as financial, government and philanthropic sectors. Scholars could study the GIIN as an intermediary, alongside other educational bodies or convening groups, and build from knowledge about convening processes across sectors (e.g., Mair and Hehenberger, 2014).

Further, institutional norms from one sector (e.g., philanthropy) may be a barrier to adopting norms of impact investing that are being established by another sector (e.g., financial or government). For example, the regulatory environment of philanthropy in the United States is high, whereby practices are driven by the desire to maintain the philanthropic organization's non-profit, tax-exempt status (Daly, 2008). Researchers could test the relationships between regulatory agencies (such as the IRS in the United States), by examining policy implementation and practice adoption. Other research could examine where specific actors, such as Blue Meridian, serve as institutional entrepreneurs (Tracey, Phillips and Jarvis, 2011) and their ability to broaden impact investing practices accepted within the philanthropic sector. 
Understanding how philanthropic organizations not only practice impact investing but also become pioneers for others to follow will be important contributions to both academic and practitioner audiences.

Another practitioner-driven question is how philanthropic organizations straddle both market and charitable orientations in a way that serves both mission and sustainability of the organization. Our academic knowledge about how philanthropic organizations carry certain institutional logics, the shared beliefs that legitimize the value of specific goals and interests (Thornton, Ocasio and Lounsbury, 2012), can be used to explain the integration of impact investing into the philanthropic sector. The philanthropic sector may have a set of institutional logics built from charitable norms, whereas impact investing involves a logic that puts financial logic as a core value alongside a charitable logic. How philanthropic organizations engage in the institutional work (Gawer and Phillips, 2013) of integrating impact investing practices and shift how different institutional logics are accepted within the philanthropic sector remains an open question. Certain philanthropic organizations, such as The Rockefeller Foundation, ${ }^{8}$ are well known and carry the characteristics of institutional entrepreneurs, actors who leverage resources to create new or transform existing institutions (Battilana, Leca and Boxenbaum, 2009; DiMaggio and Powell, 1983; Garud, Gehman and Giuliani, 2015). They can actively utilize their power within the philanthropic sector to promote impact investing but also to challenge the prevailing institutional logics. How and with what consequences are these changes possible remain important scholarly questions.

As institutions change, another question this context may shed light on is how the philanthropic sector adopts new practices yet remains core to its origins. In other words, how will the philanthropic sector stay true to its core mission of generating financial support to address social and environmental concerns, while also navigating the integration of new practices that require considerations outside of their core mission? Process-focused studies (Langley et al., 2013) that examine multiple actors over time may be able to examine how collaborating across institutions may help to answer why some actors are positioned well to adopt certain practices while others are not.

Finally, the institutional level of analysis also examines factors exogeneous to the organization or individual. Exogeneous shocks can be fast moving, such as pandemics that shock the global economy and society at rampant rates, or slower and more incremental, such as climate change or economic turmoil. While these shocks alter the way in which all institutions operate, they also escalate the social need as they strain existing social safety nets. These 
factors may amplify or suppress the momentum to adopt new practices like impact investing that emphasize a social and environmental return alongside a financial one. Learning from historic shocks, such as the US financial crisis that began in 2007 or the COVID-19 pandemic beginning in 2020, may help uncover the mechanisms for understanding when and how organizations may turn away from prior practices and look towards impact investments or vice versa.

\section{Conclusion}

As private markets increasingly address social and environmental issues, there is a growing call for the philanthropic sector to innovate and evolve alongside other funders, particularly in the practice of impact investing (Moody, 2008). While impact investing purports to be a funding strategy to help philanthropic organizations meet societal needs in a more fiscally sustainable manner, relatively few philanthropic organizations are engaging in these practices. It is important for scholars to study the intersection of philanthropy and impact investing to understand what opportunities and barriers exist at this nexus. This chapter provides an overview of the philanthropic sector and describes opportunities and challenges in integrating impact investing practices. In doing so, we illustrate nuanced differences in organizations that comprise the philanthropic sector, and present opportunities for future research at the intersection of philanthropy and impact investing. We see an opportunity for scholars across different levels of analysis to continue the path towards theoretically meaningful knowledge that addresses the current and changing reality of the financial and philanthropic landscapes.

\section{Notes}

1. See https://www.unitedway.org/; accessed 16 January 2021.

2. See https://www.fordfund.org/; accessed 16 January 2021.

3. See https://www.coca-colacompany.com/shared-future/coca-cola-foundation/; accessed 16 January 2021.

4. See https://www.gatesfoundation.org/; accessed 16 January 2021.

5. Informal interview, foundation executive director, 2015.

6. See ttps://www.bluemeridian.org/; accessed 16 January 2021.

7. See https://zomalab.com/; accessed 16 January 2021.

8. See https://www.rockefellerfoundation.org; accessed 16 January 2021. 


\section{References}

Agrawal, A. and Hockerts, K. (2019). Impact investing: review and research agenda. Journal of Small Business and Entrepreneurship, 1-29, https://doi.org/10.1080/ 08276331.2018.1551457.

Albert, S. and Whetten, D.A. (1985). Organizational identity. Research in Organizational Behavior, 7, 263-95.

Aldrich, H.E. and Fiol, C.M. (1994). Fools rush in? The institutional context of industry creation. Academy of Management Review, 19(4), 645-70.

Arrillaga-Andreessen, L. and Hoyt, D. (2004). Venture philanthropy summit overview. Stanford Business School Case Studies, No. SI-73.

Ashforth, B.E., Rogers, K.M. and Corley, K.G. (2011). Identity in organizations: exploring cross-level dynamics. Organization Science, 22(5), 1144-56.

Ashforth, B.E., Schinoff, B.S. and Brickson, S.L. (2020). My company is friendly, 'mine's a rebel': anthropomorphism and shifting organizational identity from 'what' to 'who'. Academy of Management Review, 45(1), 29-57.

Azoulay, P., Fons-Rosen, C. and Graff Zivin, J.S. (2019). Does science advance one funeral at a time? American Economic Review, 109(8), 2889-920.

Balboni, E. and Berenbach, S. (2014). Fixed income securities. In L.M. Salamon (ed.), New Frontiers of Philanthropy: A Guide to the New Tools and New Actors That Are Reshaping Global Philanthropy and Social Investing (pp. 341-65). New York: Oxford University Press.

Barney, J.B., Bunderson, J.S. and Foreman et al. (1998). A strategy conversation on the topic of organization identity. In D.A. Whetten and P.C. Godfrey (eds), Identity in Organizations: Building Theory Through Conversations (pp. 99-168). Thousand Oaks, CA: SAGE.

Batson, C.D. and Powell, A.A. (2003). Altruism and prosocial behavior. In T. Millon and J. Lerner (eds), Handbook of Psychology: Personality and Social Psychology, Vol. 5 (pp. 282-387). Hoboken, NJ: John Wiley \& Sons.

Battilana, J. and Dorado, S. (2010). Building sustainable hybrid organizations: the case of commercial microfinance organizations. Academy of Management Journal, 53(6), 1419-40.

Battilana, J., Leca, B. and Boxenbaum, E. (2009). How actors change institutions: towards a theory of institutional entrepreneurship. Academy of Management Annals, 3(1), 65-107.

Bell, A. (2013, 30 July). Why impact investing is an emerging paradigm shift in philanthropy. Forbes. Accessed 15 January 2021 at https://www.forbes.com/sites/ skollworldforum/2013/07/30/why-impact-investing-is-an-emerging-paradigm-shift -in-philanthropy/?sh=5f8174372aaa.

Bird, B. (1988). Implementing entrepreneurial ideas: the case for intention. Academy of Management Review, 13(3), 442-53.

Boeker, W. (1989). Strategic change: the effects of founding and history. Academy of Management Journal, 32(3), 489-515.

Bolis, M. and West, C. (2017). Marginalized returns. Stanford Social Innovation Review, 15(4), 55-7.

Borins, S. (2002). Leadership and innovation in the public sector. Leadership \& Organization Development Journal, 23(8), 467-75.

Brest, P. and Born, K. (2013, 14 August). Unpacking the impact in impact investing. Stanford Social Innovation Review. Accessed 15 January 2021 at https://ssir.org/up_for _debate/article/impact_investing. 
Brown, M. and Metter, R. (2019). Giving USA 2019: The Annual Report on Philanthropy for the Year 2018. Chicago, IL: Giving USA Foundation.

Brown, W.O., Helland, E. and Smith, J.K. (2006). Corporate philanthropic practices. Journal of Corporate Finance, 12(5), 855-77.

Bugg-Levine, A. and Emerson, J. (2011). Impact investing: transforming how we make money while making a difference. Innovations: Technology, Governance, Globalization, 6(3), 9-18.

Cain, D.M., Dana, J. and Newman, G.E. (2014). Giving versus giving in. The Academy of Management Annals, 8(1), 505-33.

Calabrese, T.D. and Ely, T.L. (2017). Understanding and measuring endowment in public charities. Nonprofit and Voluntary Sector Quarterly, 46(4), 859-73.

Carroll, G.R. and Hannan, M.T. (2004). The Demography of Corporations and Industries. Princeton, NJ: Princeton University Press.

Cha, W. and Abebe, M.A. (2016). Board of directors and industry determinants of corporate philanthropy. Leadership \& Organization Development Journal, 37(5), 672-88.

Cobb, N.K. (2002). The new philanthropy: its impact on funding arts and culture. The Journal of Arts Management, Law, and Society, 32(2), 125-43.

Coffey, B.S. and Wang, J. (1998). Board diversity and managerial control as predictors of corporate social performance. Journal of Business Ethics, 17(14), 1595-603.

Cortimiglia, M.N., Ghezzi, A. and Frank, A.G. (2016). Business model innovation and strategy making nexus: evidence from a cross-industry mixed-methods study. R\&D Management, 46(3), 414-32.

Costa, E. and Pesci, C. (2016). Social impact measurement: why do stakeholders matter? Sustainability Accounting, Management and Policy Journal, 7(1), 99-124.

Council on Foundations (2021). Community foundations. Accessed 16 January 2021 at https://www.cof.org/foundation-type/community-foundations-taxonomy.

Daly, S. (2008). Institutional innovation in philanthropy: community foundations in the UK. VOLUNTAS: International Journal of Voluntary and Nonprofit Organizations, 19(3), 219-41.

De Clercq, D., Fried, V.H., Lehtonen, O. and Sapienza, H.J. (2006). An entrepreneur's guide to the venture capital galaxy. Academy of Management Perspectives, 20(3), 90-112.

DiMaggio, P.J. and Powell, W.W. (1983). The iron cage revisited: institutional isomorphism and collective rationality in organizational fields. American Sociological Review, $48(2), 147-60$.

Emerson, J. (2003). The blended value proposition: integrating social and financial returns. California Management Review, 45(4), 35-51.

Emerson, J. (2018). The Purpose of Capital: Elements of Impact, Financial Flows, and Natural Being. San Francisco, CA: Blended Value Group Press.

Fidelity Charitable (2019). 2019 Annual Report. Accessed 16 January 2021 at https:// www.fidelitycharitable.org/content/dam/fc-public/docs/annual-reports/2019-annual -report.pdf.

Foreman, P. and Whetten, D.A. (2002). Members' identification with multiple-identity organizations. Organization Science, 13(6), 618-35.

Garud, R., Gehman, J. and Giuliani, A.P. (2015). Contextualizing entrepreneurial innovation: a narrative perspective. IEEE Engineering Management Review, 43(1), 80-102.

Gawer, A. and Phillips, N. (2013). Institutional work as logics shift: the case of Intel's transformation to platform leader. Organization Studies, 34(8), 1035-71.

Gersick, K.E., Stone, D. and Grady, K. et al. (2004). Generations of Giving: Leadership and Continuity in Family Foundations. Lanham, MD: Lexington Books. 
Glänzel, G. and Scheuerle, T. (2016). Social impact investing in Germany: current impediments from investors' and social entrepreneurs' perspectives. VOLUNTAS: International Journal of Voluntary and Nonprofit Organizations, 27(4), 1638-68.

Global Impact Investing Network (GIIN) (2019). Impact Investing: A Guide to This Dynamic Market. Accessed 27 April 2020 at https://thegiin.org/assets/documents/ GIIN_impact_investing_guide.pdf.

Graddy, E. and Wang, L. (2009). Community foundation development and social capital. Nonprofit and Voluntary Sector Quarterly, 38(3), 392-412.

Grant, A.M. and Berry, J.W. (2011). The necessity of others is the mother of invention: intrinsic and prosocial motivations, perspective taking, and creativity. Academy of Management Journal, 54(1), 73-96.

Gregory, N. (2016). De-risking impact investing. World Economics, 17(2), 143-58.

Gripne, S.L., Kelley, J. and Merchant, K. (2016). Laying the groundwork for a national impact investing marketplace. The Foundation Review, 8(5), https://doi.org/10.9707/ 1944-5660.1341.

Guth, W.D. and Ginsberg, A. (1990). Guest editors' introduction: corporate entrepreneurship. Strategic Management Journal, 11, 5-15.

Hatch, M.J. and Schultz, M. (1997). Relations between organizational culture, identity and image. European Journal of Marketing, 31(5/6), 356-65.

Heaphy, E.D., Byron, K. and Ballinger, G.A. et al. (2018). Introduction to special topic forum: the changing nature of work relationships. Academy of Management Review, 43(4), 558-69.

Hebb, T. (2013). Impact investing and responsible investing: what does it mean? Journal of Sustainable Finance \& Investment, 3(2), 71-4.

Hehenberger, L., Mair, J. and Metz, A. (2019). The assembly of a field ideology: an idea-centric perspective on systemic power in impact investing. Academy of Management Journal, 62(6), 1672-704.

Höchstädter, A.K. and Scheck, B. (2015). What's in a name: an analysis of impact investing understandings by academics and practitioners. Journal of Business Ethics, 132(2), 449-75.

Jaskyte, K., Amato, O. and Sperber, R. (2018). Foundations and innovation in the nonprofit sector. Nonprofit Management and Leadership, 29(1), 47-64.

Jeong, Y.C. and Kim, T.Y. (2019). Between legitimacy and efficiency: an institutional theory of corporate giving. Academy of Management Journal, 62(5), 1583-608.

Kanter, B. and Sherman, A. (2016). The Happy, Healthy Nonprofit: Strategies for Impact Without Burnout. Hoboken, NJ: John Wiley \& Sons.

Koh, H., Karamchandani, A. and Katz, R. (2012). From Blueprint to Scale: The Case for Philanthropy in Impact Investing. Monitor Group.

Langley, A.N.N., Smallman, C., Tsoukas, H. and Van de Ven, A.H. (2013). Process studies of change in organization and management: unveiling temporality, activity, and flow. Academy of Management Journal, 56(1), 1-13.

Letts, C.W., Ryan, W. and Grossman, A. (1997). Virtuous capital: what foundations can learn from venture capitalists. Harvard Business Review, 75, 36-50.

Lungeanu, R. and Ward, J.L. (2012). A governance-based typology of family foundations: the effect of generation stage and governance structure on family philanthropic activities. Family Business Review, 25(4), 409-24.

Mair, J. and Hehenberger, L. (2014). Front-stage and backstage convening: the transition from opposition to mutualistic coexistence in organizational philanthropy. Academy of Management Journal, 57(4), 1174-200.

Markus, H.R. and Kitayama, S. (1991). Culture and the self: implications for cognition, emotion, and motivation. Psychological Review, 98(2), 224-53.

Marquis, C. and Tilcsik, A. (2013). Imprinting: toward a multilevel theory. Academy of Management Annals, 7(1), 195-245. 
Merriam-Webster (n.d.). Philanthropy. Accessed June 2020 at https://www.merriam -webster.com/dictionary/philanthropy.

Mintz, J. and Ziegler, C. (2013). Mission-Related Investing: Legal and Policy Issues to Consider Before Investing. Macarthur Foundation. Accessed 12 February 2020 at https://www.macfound.org/media/article_pdfs/Mission-Related_Investing.pdf.

Moody, M. (2008). 'Building a culture': the construction and evolution of venture philanthropy as a new organizational field. Nonprofit and Voluntary Sector Quarterly, 37(2), 324-52.

Mudaliar, A., Bass, R., Dithrich, H. and Nova, N. (2019). Annual Impact Investor Survey. Global Impact Investing Network (GIIN).

Mudaliar, A. and Dithrich, H. (2019). Sizing the Impact Investing Market. Global Impact Investing Network (GIIN).

Onek, M. (2017, 11 April). Now is the time for foundations to invest for mission and impact. Stanford Social Innovation Review. Accessed 16 January 2021 at https://ssir .org/articles/entry/now_is_the_time_for_foundations_to_invest_for_mission_and _impact.

Payton, R.L. and Moody, M.P. (2008). Understanding Philanthropy: Its Meaning and Mission. Bloomington, IN: Indiana University Press.

Phillips, N., Lawrence, T.B. and Hardy, C. (2000). Inter-organizational collaboration and the dynamics of institutional fields. Journal of Management Studies, 37(1), https://doi .org/10.1111/1467-6486.00171.

Porter, M.E. and Kramer, M.R. (1999). Philanthropy's new agenda: creating value. Harvard Business Review, 77, 121-31.

Pratt, M.G. (2016). Hybrid and multiple organizational identities. In M.G. Pratt, M. Schultz, B.E. Ashforth and D. Ravasi (eds), The Oxford Handbook of Organizational Identity (pp. 106-20). Oxford: Oxford University Press.

Pratt, M.G., Schultz, M., Ashforth, B.E. and Ravasi, D. (eds) (2016). Introduction: organizational identity, mapping where we have been, where we are, and where we might go. In M.G. Pratt, M. Schultz, B.E. Ashforth and D. Ravasi (eds), The Oxford Handbook of Organizational Identity (pp. 1-19). Oxford: Oxford University Press.

Rath, J. and Schuyt, T. (2014). Entrepreneurial philanthropy: an exploratory review. The Journal of Wealth Management, 17(3), 35-46.

Rawhouser, H., Cummings, M. and Newbert, S.L. (2019). Social impact measurement: current approaches and future directions for social entrepreneurship research. Entrepreneurship Theory and Practice, 43(1), 82-115.

Reddy, C.D. (2015). Social entrepreneurship and venture philanthropy: a conceptual framework. Paper presented at the SAIMS 27th Annual Conference: Management in Southern Africa: Change, Challenge and Opportunity, Cape Town, South Africa.

Reich, K. (2019). What It Really Takes to Influence Funder Practice. Ford Foundation. Accessed 16 January 2021 at https://www.fordfoundation.org/media/4915/build -influence-funder-practice-report-121719.pdf.

Roth, B.N. (2020). Impact investing: a theory of financing social enterprises. Harvard Business School Working Paper, No. 20-078, p. 40.

Roundy, P., Holzhauer, H. and Dai, Y. (2017). Finance or philanthropy? Exploring the motivations and criteria of impact investors. Social Responsibility Journal, 13(3), https://doi.org/10.1108/SRJ-08-2016-0135.

Saiia, D.H., Carroll, A.B. and Buchholtz, A.K. (2003). Philanthropy as strategy: when corporate charity 'begins at home'. Business and Society, 42(2), 169-201.

Sanders, W.G. and Tuschke, A. (2007). The adoption of institutionally contested organizational practices: the emergence of stock option pay in Germany. Academy of Management Journal, 50(1), 33-56. 
Sansing, R. (2010). Distribution policies of private foundations. In B.A. Seaman and D.R. Young (eds), Handbook of Research on Nonprofit Economics and Management (pp. 42-58). Cheltenham, UK and Northampton, MA, USA: Edward Elgar Publishing.

Sansing, R. and Yetman, R. (2006). Governing private foundations using the tax law. Journal of Accounting and Economics, 41(3), 363-84.

Santos, F., Pache, A.C. and Birkholz, C. (2015). Making hybrids work: aligning business models and organizational design for social enterprises. California Management Review, 57(3), 36-58.

Sapienza, H.J. and Gupta, A.K. (1994). Impact of agency risks and task uncertainty on venture capitalist-CEO interaction. Academy of Management Journal, 37(6), 1618-32.

Schein, E.H. (1983). The role of the founder in creating organizational culture. Organizational Dynamics, 12(1), 13-28.

Serafeim, G. (2018). Investors as stewards of the commons? Journal of Applied Corporate Finance, 30(2), 8-17.

Shepherd, D. (2015). Party on! A call for entrepreneurship research that is more interactive, activity based, cognitively hot, compassionate, and prosocial. Journal of Business Venturing, 30(4), 489-507.

Sluss, D.M. and Ashforth, B.E. (2007). Relational identity and identification: defining ourselves through work relationships. Academy of Management Review, 32(1), 9-32.

Tekula, R. and Shah, A. (2016). Funding social innovation. In O.M. Lehner (ed.), Routledge Handbook of Social and Sustainable Finance (pp. 125-36). Abingdon: Routledge.

Thornton, P.H., Ocasio, W. and Lounsbury, M. (2012). The Institutional Logics Perspective: A New Approach to Culture, Structure, and Process. Oxford: Oxford University Press.

Tilcsik, A. (2013). Remembrance of things past: individual imprinting in organizations. Doctoral dissertation. Harvard University.

Tracey, P., Phillips, N. and Jarvis, O. (2011). Bridging institutional entrepreneurship and the creation of new organizational forms: a multilevel model. Organization Science, 22(1), 60-80.

Trelstad, B. (2016). Making sense of the many kinds of impact investing. Harvard Business Review. Accessed 20 November 2018 at https://hbr.org/2016/01/making-sense-of-the -many-kinds-of-impact-investing.

Van Slyke, D.M. and Newman, H.K. (2006). Venture philanthropy and social entrepreneurship in community redevelopment. Nonprofit Management and Leadership, 16(3), 345-68.

Wagner, L. (2016). Diversity and Philanthropy: Expanding the Circle of Giving: Santa Barbara, CA: ABC-CLIO.

Waldron, T.L., Fisher, G. and Pfarrer, M. (2016). How social entrepreneurs facilitate the adoption of new industry practices. Journal of Management Studies, 53(5), 821-45.

Wexler, R. and Fei, R. (2019). Legal explanation of program related investments. Adler \& Covin. Accessed 16 January 2021 at https://www.adlercolvin.com/wp-content/themes/ adlercolvin/pdf/Legal-Explanation-of-Program-Related-Investments-PRI-Primer.pdf.

Wood, D. and Hagerman, L. (2010). Mission investing and the philanthropic toolbox. Policy and Society, 29(3), 257-68.

Wright, K. (2001). Generosity vs. altruism: philanthropy and charity in the United States and United Kingdom. VOLUNTAS: International Journal of Voluntary and Nonprofit Organizations, 12(4), 399-416.

Wry, T. and Haugh, H. (2018). Brace for impact: uniting our diverse voices through a social impact frame. Journal of Business Venturing, 33(5), 566-74. 